\title{
Measurement of Photosynthetic Gas Exchange in Controlled Environments
}

\author{
Cary A. Mitchell \\ Center for Plant Environmental Stress Physiology, Department of Horticulture, Purdue University, \\ West Lafayette, IN 47907
}

Early controlled-environment research used growth chambers primarily as "photoperiod rooms" to study effects of environment on long-term plant developmental processes (Downs and Hellmers, 1975). More recently, growth dynamics analysis has been used to measure photosynthetic productivity of crop canopies or individual plants in controlled environments over periods of only a few days (Knight and Mitchell, 1983). However, as the emphasis of controlled-environment research shifts toward definition of optimum growth conditions (Hoff et al., 1982), there will be increasing demand to measure instantaneous photosynthetic response within modified controlled environments.

Net photosynthesis and respiration are measured most conveniently as $\mathrm{CO}_{2}$ consumption or evolution, respectively, by a given area or mass of plant tissue over a defined period. At $\approx 350$ $\mu \mathrm{mol} \cdot \mathrm{mol}^{-1}\left(\mu \mathrm{l} \cdot \mathrm{liter}{ }^{-1}, \mathrm{vpm}\right), \mathrm{CO}_{2}$ is a trace gas compared to the major components of air $\left(\mathrm{N}_{2}, \mathrm{O}_{2}, \mathrm{H}_{2} \mathrm{O}_{v}\right)$. As such, $\mathrm{CO}_{2}$ is detectable to $1 \mu \mathrm{mol} \cdot \mathrm{mol}^{-1}$ by thermal conductivity gas chromatography (TCD-GC) or infrared gas analysis. The infrared gas analyzer (IRGA) is amenable to continuous-flow monitoring of the $\mathrm{CO}_{2}$ level in air and will detect near-real-time changes in gas-exchange rate by plants as environmental conditions vary. Modem electronic detector systems permit a degree of miniaturization of IRGAs that allows their portability into growth chambers as well as to the field.

Gas exchange by chamber-grown plants may be measured for individual attached leaves, entire shoots, or leaf canopies of multiple plants. Various plant enclosure techniques are used for each type of measurement. Because a limited number of off-the-shelf assimilation chambers are available on the commercial market, many researchers have developed their own cuvettes for specific applications. Assimilation chambers often are constructed from transparent acrylic (plexiglass) or polycarbonate (mylar) plastic. Because these plastics adsorb water vapor $\left(\mathrm{H}_{2} \mathrm{O}_{v}\right)$ and, consequently, $\mathrm{CO}_{2}$

Received for publication 22 July 1991. The cost of publishing this paper was defrayed in part by the payment of page charges. Under postal regulations, this paper therefore must be hereby marked advertisement solely to indicate this fact.
(Bloom et al., 1980), it is advisable to coat internal chamber surfaces with transparent teflon tape. Closed-cell foam frequently is used to seal petioles, individual leaf blades, or fixed areas of leaves within a cuvette. It is important that gasket material be soft and flexible since physical pressure on lamina, petioles, and stems during sealing may significantly impair translocation, cause stomata1 closure, and inhibit growth (Geiger, 1974; Mitchell et al., 1975; Pappas and Mitchell, 1985). Most assimilation chambers rely on ambient growth chamber lighting to drive photosynthesis.

\section{Closed systems}

The simplest assimilation chambers are hand-held, clamp-on devices adapted for withdrawal of air samples to be subsequently injected into a GC or IRGA. If lacking in temperature control, they rely on rapid $\mathrm{CO}_{2}$ depletion by the enclosed leaf to provide a detectable change before significant "greenhouse effect" heating occurs. Most procedures traditionally permit $<10 \%$ drawdown of $\mathrm{CO}_{2}$ from ambient chamber air enclosed with a leaf or plant before the depletion is considered to be significant (Lang and Hällgren, 1985). Such measurements typically take from several seconds to less than a minute, depending on the size of the assimilation chamber relative to the exposed area of enclosed tissue. Manual syringe pumping can be used to mix enclosed air immediately before sampling, or the cuvette may contain a battery-powered fan that is activated by closing the lid. Parallel arrays of fishing line can be used to support the leaf in an appropriate orientation within the cuvette without interfering with air circulation and will prevent contact with fan blades during leaf flutter. If air samples are injected into a TCD-GC, $\mathrm{H}_{2} \mathrm{O}_{\mathrm{v}}$ of transpiration can be separated chromatographically from $\mathrm{CO}_{2}$ before the latter enters the detector, but if analyzed by IRGA, this cannot be done. Since $\mathrm{H}_{2} \mathrm{O}_{v}$ absorbs in some of the same infrared wave bands as $\mathrm{CO}_{2}($ e.g., at $2.7 \mu \mathrm{m})$, air may be passed through a non- $\mathrm{CO}_{2}$-absorbing desiccant such as $\mathrm{Mg}\left(\mathrm{ClO}_{4}\right)_{2}$ or $\mathrm{ZnCl}_{2}$ before entering the sample cell of the IRGA. Otherwise, $\mathrm{CO}_{2}$ concentration in the air sample could be significantly overestimated. Newer IRGAs are equipped with optical filters to separate $\mathrm{H}_{2} \mathrm{O}_{v}$ absorbance from that of $\mathrm{CO}_{2}$, thereby eliminating the need to 
redry air. For closed systems in which contained air is circulated between an assimilation chamber and an IRGA, a partial gas-flow bypass through a desiccant may be required to prevent accumulation of transpiration $\mathrm{H}_{2} \mathrm{O}_{v}$ in the assimilation chamber (Fig. 1A). Several commercial photosynthesis systems are portable, closed systems having a built-in, miniature IRGA and automatic humidity compensator. To accommodate portability, they usually do not have internal temperature control, but rely on rapid depletion of $\mathrm{CO}_{2}$ in the leaf cuvette for gas-exchange measurement. As for all closed systems, all seals must be air tight, the volume of the cuvette and associated plumbing must be known, and measurement must be rapid enough to minimize effects of changing temperature and/or $\mathrm{CO}_{2}$ concentration on the gas-exchange rate. Assimilation rate in a closed system is given by $\mathrm{Pn}=\left(\mathrm{C}_{1}-\mathrm{C}_{2}\right) /\left(\mathrm{t}_{2}-\mathrm{t}_{1}\right) \times \mathrm{v} \times 1 / \mathrm{L}$ (Sestak et al., 1971), where $\mathrm{Pn}=$ photosynthetic assimilation rate (amount of $\mathrm{CO}_{2}$ consumed per unit leaf area per unit time; e.g., $\left.\mu \mathrm{mol} \cdot \mathrm{m}^{-2} \cdot \mathrm{s}^{-1}\right) ; \mathrm{C}_{1}$ and $\mathrm{C}_{2}=\mathrm{CO}_{2}$ concentration at times $\mathrm{t}_{1}$ and $\mathrm{t}_{2}$ (e.g., $\mu \mathrm{mol} \mathrm{CO}_{2} / \mathrm{mol}$ atmosphere); $\mathrm{v}=$ total system volume $\left(\mathrm{m}^{3}\right)$; and $\mathrm{L}=$ leaf area $\left(\mathrm{m}^{2}\right)$. The measured photosynthetic rate should be corrected to standard temperature and pressure (STP is 0C or $273 \mathrm{~K}$ and $1 \mathrm{~atm}$ or $0.1013 \mathrm{MPa}$ ). For example, a liter of gas at $25 \mathrm{C}$ has $9.2 \%$ fewer moles than a liter of the same gas at standard temperature (0C). Without correction for temperature and pressure (especially altitude), gas-exchange rates for similar plant material would vary widely for different parts of the world.

\section{Semiclosed systems}

Another mode of measuring gas-exchange rates in growth chambers involves use of semiclosed systems. In this mode, gas recirculates between the plant enclosure chamber and IRGA, but instead of allowing $\mathrm{CO}_{2}$ to deplete, as with a completely closed system, $\mathrm{CO}_{2}$ is injected into the system at a rate that balances the rate of $\mathrm{CO}_{2}$ consumption by the plant (Fig. 1B). This "null balance" is maintained with a mass-flow controller that receives signals from the IRGA and in turn signals a proportioning valve to modulate the flow of $\mathrm{CO}_{2}$ from a compressed gas cylinder into the system. Alternatively, a solenoid valve can be actuated to keep the $\mathrm{CO}_{2}$ level within tight limits. The obvious advantage of a semiclosed system is that $\mathrm{Pn}$ can be measured at a steady-state level of $\mathrm{CO}_{2}$ in the assimilation chamber. Thus, $\mathrm{Pn}=\mathrm{f} / \mathrm{L}$ (Long and Hällgren, 1985), where $\mathrm{f}=$ flow rate of $\mathrm{CO}_{2}$ into the system (e.g., $\mu \mathrm{mol} \cdot \mathrm{s}^{-1}$ ) and $\mathrm{L}=$ leaf area $\left(\mathrm{m}^{2}\right)$ or mass $(\mathrm{g})$. As for a completely closed system, transpiration $\mathrm{H}_{2} \mathrm{O}_{v}$ should be partially absorbed with a bypass drier. The IRGA used in a semiclosed system must be an absolute rather than a differential instrument since there is no reference airstream to bypass the assimilation chamber, as with an open system. The additional complexity of a semiclosed system precludes the portability of simpler closed systems. The leaf cuvette or plant enclosure chamber is connected to the IRGA, to pumps that move air, and to flow controllers, driers, and $\mathrm{CO}_{2}$ cylinders. To avoid cluttering the growth chamber and exposing electronic instruments to high humidity in the growth area, most electronic equipment can be located outside the growth chamber, connected to the assimilation chamber by wires and tubing passing through ports.

A potential drawback of using semiclosed systems is that the investigator might be tempted to enclose plants in chambers for extended Pn measurement, since $\mathrm{CO}_{2}$ depletion would not occur. Prolonged enclosure without adequate provision for control of rising $\mathrm{O}_{2}$ concentration or scrubbing of volatile outgassing components, such as $\mathrm{H}_{2} \mathrm{O}_{v}$ and ethylene, could have a negative impact on validity of Pn measurements.

\section{Open systems}

Another type of gas-exchange system used in controlled environments is an "open" system, in which atmosphere flows through an assimilation chamber, usually after being thoroughly mixed by an internal fan before exiting the chamber at a fixed rate (Fig. 1C). A portion of the outlet gas is directed through an IRGA before being exhausted from the system, preferably out of the controlled environment entirely. The flowing atmosphere may come from one or more compressed gas cylinders, or from a pump or air compressor

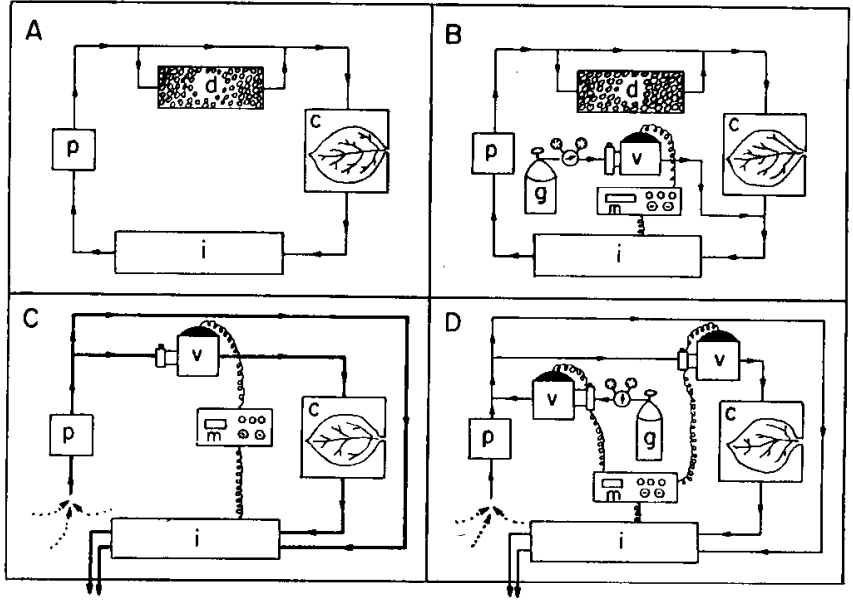

Fig. 1. Schematic representation of typical systems for measuring photosynthetic gas exchange, including (A) closed, (B) semiclosed, (C) open without $\mathrm{CO}$, injection, and (D) semi-open with $\mathrm{CO}_{2}$ injection. Lines with arrows depict direction of atmosphere flow. Heavier lines in (C) denote more rapid rates of flow than in (A) or (B), and dotted arrows represent ambient air being taken up by a pump in open systems. (c) Cuvette or assimilation chamber, (d) bypass drying column used to prevent build-up of humidity in closed systems. CD infrared CO, gas analyzer, either a differential instrument (sample + reference inlet/outlet) or an absolute measuring device (sample inlet/outlet only + sealed reference bench), (g) $\mathrm{CO}_{2}$ compressed gas cylinder, (m) mass-flow controller, (p) metal bellows pump (especially for closed systems), (v) mass-flow control valve.

delivering ambient atmosphere. Depending on the irradiated area of photosynthetic tissue within the assimilation chamber, turnover rate of atmosphere may have to be fairly rapid to prevent unwanted drawdown of $\mathrm{CO}_{2}$ using an open system without $\mathrm{CO}_{2}$ injection.

The IRGA usually is operated in a differential mode for an open system, although measurement in an absolute mode is feasible with appropriate bypass lines and valves. In a differential mode, the airstream is split before entering the cuvette, and one line bypasses the plant chamber altogether. The outlet airstream passes through the sample cell of a differential IRGA, while the bypass airstream passes through the reference cell. The IRGA detects the net $\mathrm{CO}_{2}$ concentration difference between sample and reference cells. If an absolute IRGA is used, sample and bypass airstreams are read alternately, with the one not read being vented from the system. Gas used in open systems may need to be humidified before entering the plant cuvette, because turnover rate must be rapid enough that $\mathrm{CO}_{2}$ depletion is not large, and outlet gas may or may not have to be redried before entering the IRGA, depending on the sensitivity of the IRGA to $\mathrm{H}_{2} \mathrm{O}_{v}$. The assimilation chamber of an open system often is air-conditioned to help maintain steady-state gas-exchange rates. A difference in $\mathrm{CO}_{2}$ concentration between inlet and outlet airstreams of only a few micromoles per mole is needed to determine steady-state gas-exchange rate, which is expressed as $\mathrm{Pn}=$ $\mathrm{f}\left(\mathrm{C}_{\mathrm{i}}-\mathrm{C}_{\mathrm{o}}\right) / \mathrm{L}$ (Sestak et al., 1971), where $\mathrm{C}_{\mathrm{i}}=$ inlet $\mathrm{CO}_{2}$ concentration, $\mathrm{C}_{\mathrm{o}}=$ outlet $\mathrm{CO}_{2}$ concentration, $\mathrm{f}=$ flow rate of air through the system, and $\mathrm{L}=$ leaf area or mass.

\section{Semi-open systems}

A specialized type of open gas-exchange system involves slow turnover of the atmosphere but separate injection of $\mathrm{CO}_{2}$ to maintain a steady-state $\mathrm{CO}_{2}$ level (Fig. 1D). This type of open system uses far less ventilating gas than does an open system. Minitron chambers (Akers et al., 1985; Knight et al., 1988) may be adapted to operate in various modes, including semi-open. Single or several plants can be grown hydroponically in Minitrons and shoot and root compartments sufficiently isolated from each other to measure gas exchange in both compartments separately (Fig. 2). An internal air circulation/cooling system, including fan, heat-exchange coils, and baffle, prevents stratification of air and temperature within cham- 


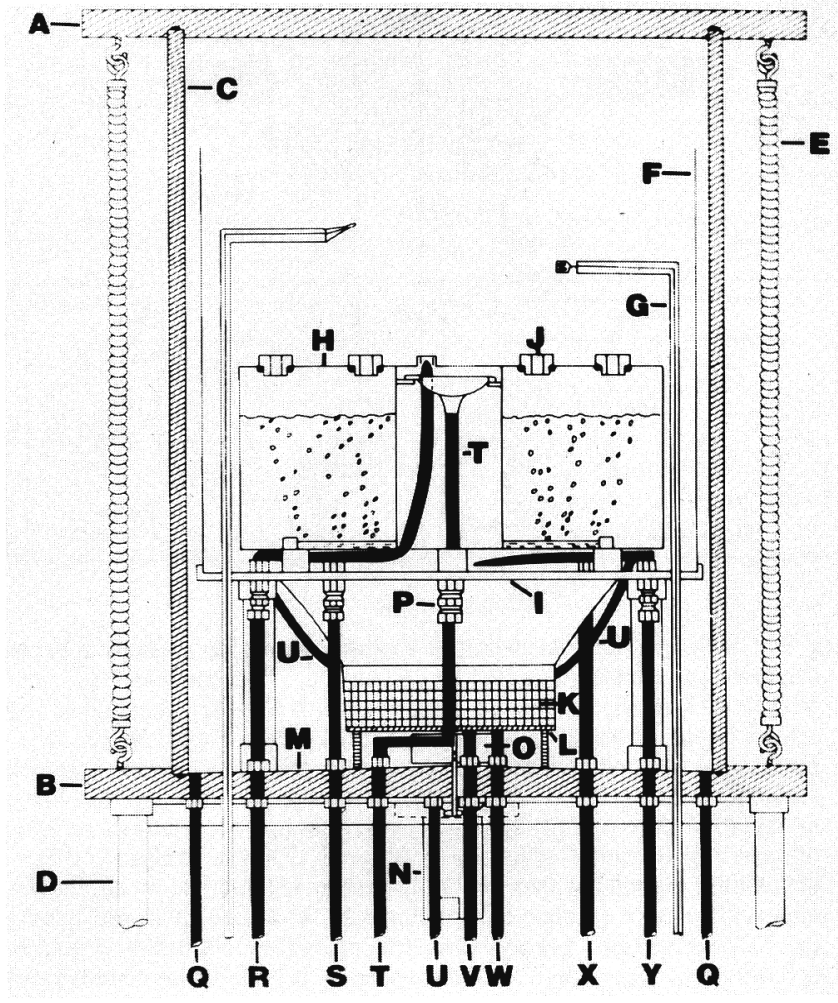

Fig. 2. Schematic side view of a Minitron II chamber. The cylinder is $63.5 \mathrm{~cm}$ high with a $61.2 \mathrm{~cm}$ o.d. and has an internal volume of 0.151 ma, excluding internal accessories. (A) lid, (B) base, (C) cylinder, (D) height-adjustable, threaded metal legs, (E) tension springs, (F) air-flow baffle, (G) height/position-adjustable thermistor, $(\mathrm{H})$ hydroponics container, (I) hydroponics container platform, (J) plant holder with closedcell plug in middle, (K) automobile core heat exchanger, (L) heat-exchanger platform, (M) outward-sloping floor, (N) fan motor, (0) fan blades, (P) bulk-head fittings for portals in base, (Q) condensate drain from chamber, (R) rhizosphere outlet, $(\mathrm{S})$ nutrient solution inlet, $(\mathrm{T})$ shoot atmosphere outlet, (U) inlet for nutrient solution aeration, (V) coolant inlet, (W) coolant outlet, (X) nutrient solution outlet, (Y) shoot atmosphere inlet (Knight et al., 1988).

bers. To achieve $\mathrm{CO}_{2}$ enrichment, separate mass-flow control systems inject $\mathrm{CO}_{2}$ and air into a mixing chamber upstream from the inlet to the shoot compartment (Fig. 3), although $\mathrm{CO}_{2}$ injection theoretically could take place directly into an assimilation chamber in which air is well stirred. Outlet atmosphere can be monitored for water vapor content by dewpoint hygrometry and for $\mathrm{CO}_{2}$ by infrared gas analysis. A computer-assisted, mass-flow control system coupled with an IRGA can maintain steady-state $\mathrm{CO}_{2}$ concentration within Minitron chambers using a proportional-integral-derivative control program. Carbon dioxide consumption rate is proportional to the voltage signal required to drive a proportioning valve to an aperture that maintains steady-state $\mathrm{CO}_{2}$ level in the chamber containing photosynthesizing plants. Canopy gas exchange is determined as the difference in voltage signal to the proportioning valve required to maintain a given $\mathrm{CO}_{2}$ concentration in an empty Minitron with a slow turnover atmosphere and one containing plants. An advantage of such a system is that plants can be measured for gas exchange in the very environment in which they grow, without changing environmental conditions and without clamping a cuvette around the leaves. The assimilation chamber is the growth chamber.

\section{Lighting considerations for gas exchange in growth chambers}

Lighting for transparent gas-exchange cuvettes or assimilation chambers can be provided by lamps mounted on the ceiling of a controlled-environment room housing the system, or by lamp banks mounted above the enclosure chamber(s). An advantage of using "ambient" growth chamber lighting for gas-exchange measurement is that it is representative of the radiation environment to which the plants already are adapted. However, construction material for enclosure chambers (plastic, glass, etc.) will modify the spectral quality of incident radiation from lamps in growth rooms. Both longwave and ultraviolet radiation can be attenuated by chamber wall and lid material. Special UV-transmitting acrylics can be obtained for constructing enclosure chambers. If high irradiance is used to drive photosynthesis, lamp radiation can be filtered through longwave-absorbing material or several centimeters of water to remove thermal wave bands that otherwise would enter assimilation chambers. This thermal filter precludes a much greater heat load on any internal air-conditioning system, thereby allowing heat-exchange coils to be maintained at a temperature closer to ambient and causing less dehumidification resulting from condensation of water in the chamber.

\section{General considerations for gas-exchange measurement}

If one wishes to monitor photosynthesis under the full spectrum of lamp radiation unattenuated by assimilation chamber surfaces, it is possible to adapt the growth chamber itself to be a large gasexchange cuvette. By rigorously sealing all potential leak points in the chamber (e.g., with silicon sealant), installing an inlet port for make-up gas and an outlet port and pump to an IRGA, and maintaining the chamber under slight positive pressure, it is possible to monitor net photosynthesis of the-contained crop canopy (Bugbee and Salisbury, 1986). A good internal air-circulation system is important to assure that sampled atmosphere is representative. Since the presence of a single person in a walk-in growth room can raise the $\mathrm{CO}_{2}$ level hundreds of parts per million in several minutes, access by personnel to the interior of a walk-in or stand-in chamber adapted for gas exchange normally must be denied during measurement if the system is to be operated near normal ambient. However, if human presence in such an adapted chamber cannot be avoided, exhalation breath must be absorbed by a face mask and/ or directed out of the chamber through a hose. Furthermore, skin respiration would require full suit enclosure of workers to avoid, perturbation of $\mathrm{CO}_{2}$ level in the chamber atmosphere for precise work.

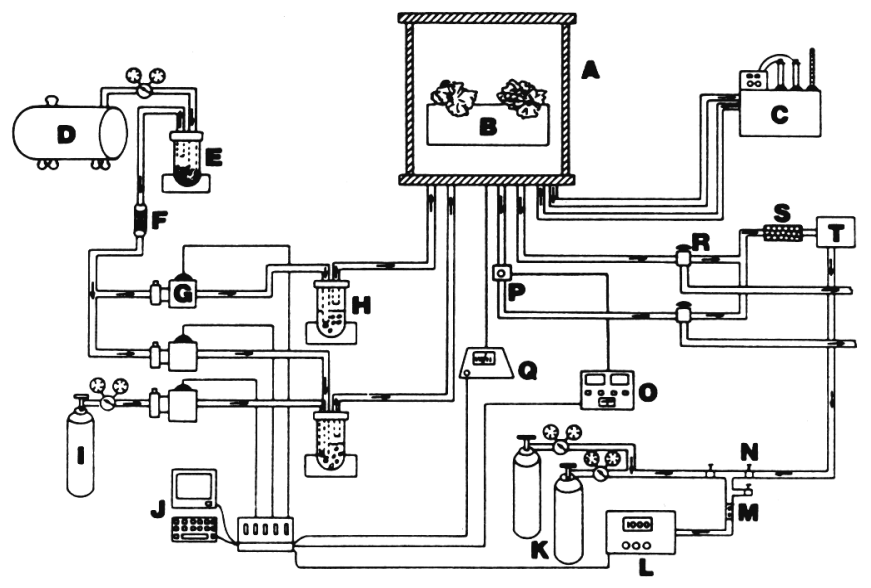

Fig. 3. Schematic of Minitron II environmental control and monitoring systems. (A) chamber, (B) root compartment, (C) thermostat-controlled, circulating water bath (Lauda model K-4R), (D) air compressor (Gast model SHCD), (E) air-drying cylinder containing $\mathrm{CaCl}_{2}$ pellets, (F) airpurifying tower containing Purafil to absorb ethylene, $(\mathrm{G})$ mass-flow controller (MKS model 1259A), (H) humidification cylinder, (I) $\mathrm{CO}_{2}$ cylinder $\left(99.95 \% \mathrm{CO}_{2}\right),(\mathrm{J})$ microcomputer (Action Instr. model BG-3), (K) calibration gas standards, (L) infrared gas analyzer (Horiba model PIR-2000), (M) rotameter (Matheson model 603), (N) needle valve, (O) dewpoint hygrometer (EG\&G model 911), (P) dewpoint remote sensor, (Q) scanning telethermometer (YSI model 47), (R) three-way valve, (S) air-drying cylinder containing $\mathrm{Mg}\left(\mathrm{ClO}_{4}\right)_{2}$, (T) booster pump (Metal Bellows model MB-21) (Knight et al., 1988). 
Ability to monitor net photosynthesis of crop canopies in growth chambers under different combinations of environmental conditions will lead to the rapid establishment of response surfaces for optimum productivity during vegetative and reproductive phases of development for some crops, based on instantaneous gas-exchange measurements rather than long-term growth or yield.

\section{Literature Cited}

Akers, C., S. Akers, and C. Mitchell. 1985. The Minitron system for growth of small plants under controlled environment conditions. J. Amer. Soc. Hort. Sci. 110:353-357.

Bloom, A., H. Mooney, O. Böjrkman, and J. Berry. 1980. Materials and methods for carbon dioxide and water exchange analysis. Plant, Cell \& Environ. 3:371-376.

Bugbee, B.G. and F.B. Salisbury. 1986. Studies on maximum yield of wheat for the controlled environments of space, p. 447-485. In: R. MacElroy (ed.). Controlled ecological life support systems: CELSS T85 Workshop. NASA Publ. TM 88215, Ames Research Center, Moffett Fie ld, C a lif .

Downs, R. and H. Hellmers. 1975. Environment and the experimental control of plant growth. Academic, New York.
Geiger, D. 1974. Carbon-14 labeling of photosynthate as a means for studying translocation, p. 138-154. In: A. San Pietro (ed.). Experimental plant physiology. C.V. Mosby Co., St. Louis.

Hoff, J., J. Howe, and C. Mitchell. 1982. Nutritional and cultural aspects of plant species selection for a regenerative life support system. NASA Rpt. 166324

Knight, S., C. Akers, S. Akers, and C. Mitchell. 1988. Minitron II system for precise control of the plant growth environment. Photosynthetica 22(1):90-98.

Knight, S. and C. Mitchell. 1983. Stimulation of lettuce productivity by manipulation of diurnal temperature and light. HortScience 18:462-463.

Long, S. and J. Hällgren. 1985. Measurement of CO, assimilation by plants in the field and the laboratory, p. 62-99. In: J. Coombs, D. Hall, S. Long, and J. Scurlock (eds.). Techniques in bioproductivity and photosynthesis. 2nd ed. Pergamon Press, Oxford, U.K.

Mitchell, C., C. Severson, J. Wott, and P. Hammer. 1975. Seismomorphogenic regulation of plant growth. J. Amer. Soc. Hort. Sci. 100:161165.

Pappas, T. and C. Mitchell. 1985. Influence of seismic stress on photosynthetic productivity, gas exchange, and leaf diffusive resistance of Glycine $\max$ (L.) Merrill cv. Wells II. Plant Physiol. 79:285-289.

Sestak, Z., J. Catsky, and P. Jarvis. 1971. Plant photosynthetic production: Manual of methods. W. Junk, The Hague, Netherlands. 